Supporting information for

\title{
Efficient Conversion of Inulin to Inulooligosaccharides through Endoinulinase
}

\section{from Aspergillus niger}

Yanbing $\mathrm{Xu}^{1}$, Zhaojuan Zheng ${ }^{2}$, Qianqian $\mathrm{Xu}^{2}$, Qiang Yong ${ }^{2}$, Jia Ouyang ${ }^{2,3 *}$

${ }^{1}$ College of Forestry, Nanjing Forestry University, Nanjing 210037, People's

Republic of China

${ }^{2}$ College of Chemical Engineering, Nanjing Forestry University, Nanjing 210037,

People's Republic of China

${ }^{3}$ Key Laboratory of Forest Genetics \& Biotechnology of the Ministry of Education,

Nanjing, People's Republic of China

*Corresponding author.

Address: College of Chemical Engineering, Nanjing Forestry University, Nanjing

210037, People's Republic of China,

Tel.: 86-025-85427129, Fax: 86-025-85427587,

E-mail: hgouyj@njfu.edu.cn 


\section{MEDIUM FORMULAS}

Minimal dextrose medium (MD) contains the following (w/v): 1.34\% YNB, $4 \mathrm{x}$ $10^{-5} \%$ biotin, $2 \%$ dextrose and $1.5 \%(\mathrm{w} / \mathrm{v})$ agar.

Yeast peptone dextrose medium (YPD) contains the following (w/v): 1\% yeast

extract, $2 \%$ peptone, $2 \%$ glucose and $2 \%$ agar.

Buffered glycerol complex medium (BMGY) contains the following (w/v): 1\% yeast extract, $2 \%$ peptone, $100 \mathrm{mM}$ potassium phosphate ( $\mathrm{pH} 6.0$ ), 1.34\% YNB, $4 \mathrm{x}$ $10^{-5} \%$ biotin and $1 \%$ glycerol. For buffered methanol complex medium (BMMY), add $0.5 \%$ methanol instead of glycerol.

Fermentation basal salts medium (BSM) contains the following (per liter): $26.7 \mathrm{~mL}$ $85 \%$ phosphoric acid, $0.93 \mathrm{~g}$ calcium sulfate, $18.2 \mathrm{~g}$ potassium sulfate, $14.9 \mathrm{~g}$, magnesium sulfate- $7 \mathrm{H}_{2} \mathrm{O}, 4.13$ g potassium hydroxide and $40.0 \mathrm{~g}$ glycerol.

PTM1 trace salts solution contains the following (per liter): $6.0 \mathrm{~g}$ cupric sulfate- $5 \mathrm{H}_{2} \mathrm{O}, 0.08 \mathrm{~g}$ manganese sulfate- $\mathrm{H}_{2} \mathrm{O}, 3.0 \mathrm{~g}$ sodium iodide, $0.2 \mathrm{~g}$ sodium molybdate- $2 \mathrm{H}_{2} \mathrm{O}, 0.02 \mathrm{~g}$ boric acid, $0.5 \mathrm{~g}$ cobalt chloride, $20.0 \mathrm{~g}$ zinc chloride, $65.0 \mathrm{~g}$ ferrous sulfate- $7 \mathrm{H}_{2} \mathrm{O}, 0.2 \mathrm{~g}$ biotin and $5.0 \mathrm{~mL}$ sulfuric acid.

\section{NETHANOL FEEDING STRATEGY}

A methanol feeding strategy was used during the fed-batch phase. After terminated glycerol feeding, the methanol fed-batch phase was initiated by starting a $100 \%$ methanol feed containing $12 \mathrm{~mL}$ PTM1 trace salts per liter of methanol. The induction temperature was $28{ }^{\circ} \mathrm{C}$. During the first 2 hours, the feed rate was 0.43 
$\mathrm{mL} / \mathrm{h}$ per liter initial fermentation volume. When the strain was fully adapted to methanol utilization (2-4 hours) and was limited on methanol, a steady DO reading and a fast DO spike time were observed. Then, the feed rate was increased in $10 \%$ increments every 30 minutes. After 4 hours, the rate of $2.57 \mathrm{~mL} / \mathrm{h}$ was maintained during the methanol fed-batch phase. The entire methanol fed-batch phase lasted approximately $120 \mathrm{~h}$ with a total of approximately $580 \mathrm{ml}$ methanol fed in the $3 \mathrm{~L}$ fermentor. It was according to the instructions of Pichia Fermentation Process Guidelines (Invitrogen, USA). 